Unfinished Nursing Care: An Important Performance Measure for Nursing Care Systems Christopher A. VanFosson ${ }^{\mathrm{a}}$, MSN/MHA, RN, (Corresponding Author)

${ }^{a}$ Doctoral Student, The University of Texas at Austin School of Nursing, cvanfosson@utexas.edu 27003 Trinity Bend, San Antonio, Texas 78261

\author{
Terry L. Jones ${ }^{\mathrm{b}}, \mathrm{PhD}, \mathrm{RN}$, \\ ${ }^{\mathrm{b}}$ Assistant Professor, The University of Texas at Austin School of Nursing; \\ tljones@mail.nur.utexas.edu \\ Linda H. Yoder ${ }^{\mathrm{c}}$, PhD, MBA, RN, AOCN, FAAN \\ ${ }^{\mathrm{c}}$ Associate Professor, The University of Texas at Austin School of Nursing; \\ lyoder@mail.nur.utexas.edu
}

Author Note

The authors received no funding for this manuscript. The first author (CAV) attends the University of Texas at Austin on a professional scholarship from the United States Army. The views expressed in this manuscript are those of the authors and do not reflect the official policy or position of the U.S. government or the Department of Defense. 


\begin{abstract}
Performance measurement is a core administrative function and an essential component of organizational quality programs. The prevalence of performance measurement initiatives increased significantly following release of the Institute of Medicine series on quality. Nursing performance measures are limited in their scope, resulting in an underrepresentation of process measures. Development of performance indicators that reflect how effectively organizational units actually transform nursing resources into nursing services should be a high priority. Unfinished nursing care is a nursing process performance measure that reflects the complexity of the nursing care environment and can be useful in comparing process performance across systems and organizations. Unfinished nursing care is congruent with many of the National Quality Forum requirements for endorsement and warrants further refinement as an important nurse sensitive performance measure.

Keywords: unfinished nursing care, missed care, implicit rationing, tasks undone, performance measurement, nursing quality, Nursing Care Performance Framework
\end{abstract}




\section{Unfinished Nursing Care: An Important Performance Measure for Nursing Care Systems}

Performance measurement is a core administrative function and an essential component of organizational quality programs. Performance measurement quantifies performance in relation to established goals, standards, and expectations and guides improvement initiatives. The need for performance measurement in healthcare was reinforced by the Institute of Medicine (IOM) in a series of reports highlighting significant gaps between the actual and desired level of patient care quality being delivered (IOM, 1999, 2001, 2004, 2006). The IOM series provides a clear definition of quality, aims for improvement, and a charge to close the quality gap through system transformation. Quality care is defined as the right care consistently provided to the right person in the right manner at the right time (IOM, 1999). Characteristics of the right care are encapsulated in the six aims for improvement: care that is safe, effective, patient-centered, timely, efficient, and equitable. However, gaps in quality include overuse, underuse, or misuse of healthcare services. At least half of American patients experience an underuse of beneficial healthcare services making underuse the most common gap (U.S. Department of Health \& Human Services [DHHS], 2011; Schuster, McGlynn, \& Brook, 2005).

The problem of underuse in nursing (Agency for Healthcare Research and Quality [AHRQ], 2015a) is reflected in the phenomenon of unfinished nursing care (UNC), also known as implicitly rationed care (Schubert, Glass, Clarke, Shaffert-Witvliet, \& De Geest, 2007), tasks left undone (Aiken et al., 2001), and missed care (Kalisch, 2006). UNC is conceptualized as a problem of time scarcity that prompts nurses to engage in a process of clinical prioritization, also called implicit rationing, to determine which elements of necessary care are completed and which are left undone (Jones, Hamilton, \& Murry, 2015b). Necessary care is determined by nursing judgment, provider prescription, and/or professional standards (Schubert et al., 2007). 
The ability to close quality gaps and consistently achieve the six aims is severely compromised without robust performance measurement (IOM, 2006). The purposes of this paper are to: (1) identify gaps in the current measurement of nursing performance, and (2) evaluate unfinished nursing care as a potential nurse sensitive performance measure.

\section{Performance Measurement in Nursing}

The AHRQ has been a leader in the development of performance measures in healthcare since 1989. A major focus for AHRQ has been the development of standardized, evidence-based quality indicators that can be applied to administrative data. AHRQ currently supports software programs that assess performance on 101 quality indicators based on information in hospital discharge databases (AHRQ, 2015e). Today these indicators are widely used by multiple stakeholders to assess the quality of hospital care. For example, the AHRQ quality indicators are now used to generate publically reported hospital report cards, to negotiate reimbursement policies, and to guide quality improvement initiatives at the local, state, and federal level (AHRQ, 2015e). However, the AHRQ indicators are driven by the presence of coded patient diagnoses and coded services. Because nursing services are not explicitly recorded in hospital discharge databases, the capacity of the AHRQ indicators to measure nursing performance is limited. Therefore, initiatives to develop nurse-specific performance measures emerged.

Contemporary performance measurement in nursing arguably began with the American Nurses Association's (ANA) Patient Safety and Quality of Care initiative in 1994 and subsequent development of the National Database of Nursing Quality Indicators (NDNQI) in 1998 (Montalvo, 2007). Additional nursing performance measures were developed by other stakeholders such as: The California Outcomes Coalition (CalNOC; established in 1996), health plans (Kaiser Permanente Inpatient Nursing Quality Indicator Project; Alexander, 2007), the 
Department of Veteran's Affairs (Veteran's Affairs Nurse Outcomes Database [VANOD], formally established in the 2006; U.S. Department of Veterans Affairs, 2010), and the Department of Defense (Military Nurse Outcomes Database [MilNOD], established in 1997; Patrician, Loan, McCarthy, Brosch, \& Davey, 2010). Consensus standards for evaluation of performance measures now exist and the National Quality Forum (NQF) is recognized as the common pathway for review and endorsement of performance measures in healthcare (Quraishi \& Jordan, 2014). The number of candidate measures for consideration as nurse sensitive indicators (NSIs) rose to 150 by the beginning of the NQF endorsement process in 2004. Fifteen met the NQF criteria of importance, scientific acceptability, usability, and feasibility and were ultimately endorsed (see Table 1; NQF, 2004).

The application and consequences of performance measurement also have evolved. Performance measures are now an integral component of value based purchasing and transparency initiatives (Chassin, Loeb, Schmaltz, \& Wachter, 2010; Wachter, 2010). Reimbursement is tied to performance on an increasing number of measures and report cards detailing provider performance across multiple measures are publicly available (Center for Medicare \& Medicaid Services, 2015a). Inclusion of more NSIs in these initiatives is viewed as a mechanism to incentivize investments in nursing care quality (Kavanagh, Cimiotti, Abusalem, \& Coty, 2012). The effect of performance measurement is summarized in the old adage "what gets measured gets managed." The act of measurement draws attention to an issue and with attention often come resources for intervention (Elg, Broryd, \& Kollberg, 2013; Perlin, Horner, Englebright, \& Bracken, 2012). Simply stated, measurement drives prioritization practices for providers and organizations. Although engineered with positive intent, the measurement effect 
also is associated with potential unintended negative consequences (Adair et al., 2006; Powell et al., 2012).

Multiple taxonomies of unintended consequences, also known as metric-driven harm, appear in the literature (Mannion \& Braithwaite, 2012; Powell et al., 2012; Rambur, Valett, Cohen, \& Tarule, 2013; Smith, 1995). Examples of metric-driven harm include: measure fixation (focus on maximization of the measure without regard for any associated distress for patients or others) and tunnel vision (prioritization of financially incentivized and/or measured care over other valuable aspects of care). Because of the potential for metric driven harm, it is now advocated that performance measure sets contain indicators of potential unintended consequences. These measures, known as balancing measures, facilitate early identification and intervention for metric driven harm and encourage evaluation of the total system effect of improvement initiatives (Clarke, 2015).

\section{Gaps in Performance Measurement}

Nurses comprise the largest body of healthcare professionals and play a crucial role in the healthcare delivery system (U.S. Department of Labor, Bureau of Labor Statistics, 2013). They not only administer independent nursing interventions, but they also coordinate and administer interventions prescribed by physicians and other members of the healthcare team. Consequently, nurses function as gatekeepers of healthcare and nursing systems serve as important leverage points for improvement. Not surprisingly, the nurse work environment was specifically targeted for transformation (IOM, 2004). Despite the centrality of nursing in the healthcare system, two reviews concluded that the nursing profession has been largely absent from discussions of performance measurement policy (Kurtzman, Dawson, \& Johnson, 2008; Needleman, Kurtzman, \& Kizer, 2007) and it is clear that the benefits of performance measurement have yet to be 
maximized for nursing care. Only 15 of the 630 measures endorsed by NQF ( 2\%) are sensitive to the quality of nursing care (NQF, 2015). Moreover, only 3 of the 101 AHRQ indicators ( 3\%) are endorsed by the NQF as NSIs (AHRQ, 2015c, 2015d). None of the major quality performance programs include all of the endorsed NSIs (Table 2). Nursing-specific performance programs include more of the endorsed NSIs than general hospital performance programs. However, fewer hospitals participate in the nurse-specific programs. Although approximately 3100 hospitals submitted data on inpatient performance measures to The Joint Commission (TJC) in 2010, only three of the 31 publicly reported measures were NSIs (Chassin et al., 2010). The three NSIs tracked by TJC (smoking cessation counseling for patients with pneumonia, heart failure, and acute myocardial infarction) were integrated into core measure sets and are not included in any of the other major performance measurement programs. Moreover, Chassin et al. (2010) determined that these three measures did not really reflect the quality of care processes and proposed that they no longer be used for the purposes of accountability such as accreditation, public reporting, and value based purchasing. Consequently, the three nursing process measures were dropped from the core measure set and excluded from the newly adopted accountability measures (TJC, 2015c).

Endorsement of the initial 15 NSIs was an important step in development of a robust performance measurement system for nursing. Continued development and refinement of the initial measure set was anticipated but has not materialized (Kurtzman et al., 2008; Naylor, 2007; Needleman et al., 2007). A common criticism of the initial set of measures is limitation in scope; however, no additional measures have been endorsed. The NQF NSI measure set is characterized as hospital-centric with a primary focus on adverse events for selected patient populations. Moreover, process measures and measures that provide insight into patient experiences, 
efficiency, and equity are underrepresented (Alexander, 2007; Naylor, 2007). For example, smoking cessation accounts for the only three endorsed NSI process measures and these measures are no longer included in any major performance measurement program (Chassin et al., 2010). Consequently, the current endorsed measure set does not adequately reflect the complexity of the nursing care system and the range of nursing contributions to patient care (Alexander, 2007; Dubois, D’Amour, Pomey, Girard, \& Brault, 2013). The limited scope of current NSI set is a window of opportunity for the introduction of new performance measures (Quraishi \& Jordan, 2014).

Development of new measures is hindered by a poor conceptualization of how nursing services are delivered and how they potentially influence patient and organizational outcomes. Dubois et al. (2013) identified 31 different conceptual frameworks for nursing services with a combined total of 51 performance measures. Common themes consistent with a system perspective and recognition of the complex interdependencies associated with nursing services were identified across frameworks. However, wide variation in the translation and application of these theoretical threads and inconsistent use of terminology was noted. No single framework was identified that effectively captured the full scope of nursing services; therefore, each framework was associated with gaps in performance measurement. When considered collectively, however, Dubois et al. (2013) suggested that a more comprehensive and accurate conceptualization of nursing services emerged. Consequently, they proposed a synthesis of existing models into one unifying framework, the Nursing Care Performance Framework $(\mathrm{NCPF})$.

Nursing performance is broadly defined in the NCPF (Figure 1) as, "the capacity demonstrated by an organization or an organizational unit to acquire the needed nursing 
resources and use them in a sustainable manner to produce nursing services that effectively improve patients' conditions" (Dubois et al., 2013, p. 6). Three functions (subsystems) of nursing care systems are proposed: (1) acquiring, deploying, and maintaining nursing resources; (2) transforming nursing resources into nursing services; and (3) producing changes in patients' conditions. Multiple dimensions are identified under each function along with hypothesized cross-functional relationships. Examination of the current state of performance measurement in nursing through the lens of the NCPF facilitates gap analysis and identification of priorities for further measure development. None of the dimensions under any of the three functions are represented in all 31 conceptual frameworks. The first and third functions are represented most frequently. The dimensions most often associated with performance indicators include nursing staff supply and risk outcomes and safety. In contrast, the second function is represented in less than half of existing frameworks and the dimension of nursing processes is particularly underrepresented (Dubois et al., 2013).

This finding is consistent with critiques of the evidence linking nurse staffing to patient outcomes. Multiple reviews concluded that, despite consistent associations between measures of nurse staffing and patient outcomes, the causal mechanisms through which staffing influences outcomes have not been sufficiently described (Blegen, Goode, Spetz, Vaughn, \& Park, 2011; Kane, Shamliyan, Mueller, Duval, \& Wilt, 2007; Needleman, Buerhaus, Mattke, Stewart, \& Zelevinsky, 2002). Presumably nurse staffing, which encompasses the acquisition and deployment of nurses, influences patient outcomes through the capacity for appropriate and timely application of nursing processes. However, this hypothesized cross-functional relationship cannot be examined without explicit conceptualizations and robust measures of nursing processes. Therefore, development of performance indicators that reflect how effectively 
organizational units actually transform nursing resources into nursing services should be a high priority. In this context, UNC warrants continued development and consideration for endorsement as a nurse sensitive performance indicator.

\section{Unfinished Nursing Care as a Performance Indicator}

The characterization of UNC is conceptually congruent with the NCPF. UNC is a direct reflection of the dimension of nursing processes and the prevalence of UNC can be interpreted as an indication of how effectively resources are transformed into services. Specifically, higher levels of UNC suggest inadequate transformation of nursing resources into relevant nursing services. Although UNC is conceptually relevant to performance measurement in nursing, evidence related to the NQF consensus standards also must be examined. A growing body of evidence to support the importance, scientific acceptability, usability, and feasibility of measuring UNC continues to emerge. A review of this evidence is needed to guide refinement of UNC as a potential nurse-sensitive performance indicator.

\section{Importance}

The standard of importance reflects a measure's ability to identify processes that are suboptimal or where variation exists (NQF, 2004) and UNC satisfies this standard. The presence of UNC is incongruent with the IOM definition of quality and delivery of care that is personalized, safe, equitable, effective, efficient, and timely (IOM, 2001). Assuming that timely evidence-based nursing care is instrumental in achieving optimal health outcomes, it is logical to conclude that UNC places patients at risk for suboptimal health outcomes. This logic is supported by empirical evidence linking UNC with multiple adverse outcomes (Table 3) to include: medication errors (Ausserhofer, et al., 2013; Lucero, Lake, \& Aiken, 2010; Schubert et al., 2007); inpatient mortality (Schubert, Clarke, Aiken, \& De Geest, 2012); patient falls 
(Ausserhofer et al., 2013; Kalisch, Tschannen, \& Lee, 2012; Schubert et al., 2008; Schubert, Clarke, Glass, Schaffert-Witvliet, \& De Geest, 2009); pressure ulcers (Ausserhoffer et al., 2013, Schubert et al., 2009); nosocomial infections (Ausserhoffer et a;., 2013; Lucero, et al., 2009; Rochefort \& Clarke, 2010; Schubert et al., 2009); and 30 day readmissions (Brooks Carthon, Lassater, Sloane, \& Kutney-Lee, 2015). Suboptimal outcomes increase the burden on the healthcare system and society in general through increased costs and decreased productivity (IOM, 2013). Therefore, variations of UNC clearly reflect variations in the quality of patient care. UNC is highly prevalent in acute care hospitals internationally; 55-98\% of nursing staff report leaving one or more elements of nursing care unfinished (Al-Kandari \& Thomas, 2009; Ausserhoffer et al., 2013; Schubert et al., 2013). When extrapolated to the patient experience, these findings indicate that at least $55 \%$ of hospitalized patients likely do not receive the right nursing care at the right time. Moreover, variations in levels of UNC have been documented at the hospital and unit level across the United States (Jones, 2015; Kalisch, Gosselin, \& Choi, 2012; Kalisch \& Lee, 2010; Kalisch \& Lee, 2012; Kalisch, Tschannen, Lee, \& Friese, 2011) and Europe (Ausserhofer et al., 2014; Ball, Murrells, Rafferty, Morrow, \& Griffiths, 2014). This level of underuse reflects performance below the threshold for highly reliable organizations (Chassin \& Loeb, 2013) and indicates that opportunities for improvement exist.

The importance of UNC also is evident in national quality priorities established by AHRQ (2015b), IOM (2003), National Priorities Partnership (2008), and the DHHS (2011). Resolution of many improvement priorities is contingent on completion of nursing processes. National priorities that are particularly sensitive to timely completion of nursing processes include: effective communication and coordination of care; health literacy for self-management; patient and family engagement as partners in their care; medication management; safety, reliability, 
harm reduction (healthcare associated infections, preventable serious adverse events, and premature hospital mortality); and pain control. Elements of nursing care that contribute to most of these priorities include: communication and coordination with patients, families, and other members of the care team; patient and family education; emotional and psychological support; and evaluation of care. These elements of nursing care are among those most frequently left unfinished (Jones et al., 2015b; Kalisch, 2015, p. 30; Papastavrou, Andreou, Efstathiou, 2014). Therefore, improvement in these national priorities requires that UNC be monitored and addressed across practice settings.

\section{Scientific Acceptability}

Scientific acceptability refers to the capacity to provide consistent and credible estimates of performance. Compliance with this standard requires that a performance measure be well defined, valid, reliable, and adaptable (NQF, 2004). Despite the multiple terms and conceptual models used to describe UNC, recent state of the science reviews indicated that the differences in term definitions and conceptual frameworks are not clinically significant and they all reflect a singular and well defined phenomenon (Jones et al., 2015b; Papastavrou et al., 2014).

UNC is most commonly measured by nurse self-report on survey instruments. The majority of available instruments were derived from three parent surveys: the MISSCARE Survey (Kalisch \& Williams, 2009), the tasks undone survey (7 items; Aiken et al, 2001), and the Basal Extent of Rationing of Nursing Care Instrument (BERNCA; Schubert et al., 2007). UNC instruments prompt nurses to recall how often they left each activity on an inventory of nursing activities unfinished. Variation across instruments exists in the following areas: recall timeframe; size and comprehensiveness of nursing activity inventory; response scale range; scoring 
procedures; consideration of perceived task importance and delegated activities; and specific reason for unfinished care (Jones et al., 2015b; Papastavrou et al., 2014).

Support for the validity of UNC instruments is based on expert consensus, examination of the internal structures and correlation of instrument-based estimates of UNC with related concepts. Expert staff nurse panels confirmed the clarity and relevance to practice of activity items during instrument development as well as the overall comprehensiveness of selected inventories (Jones, 2014; Kalisch \& Williams, 2009; Rochefort \& Clarke, 2010; Schubert et al., 2007). Stable internal structures consisting of single factor solutions were supported by exploratory factor analyses for instruments derived from the MISSCARE and BERNCA instruments (Ausserhofer et al., 2013; Castner, Wu, \& Dean-Baar, 2014; Jones, 2014; Rochefort \& Clarke, 2010). As indicated in Table 3, moderate correlations between estimates of UNC and related aspects of the nurse work environment assessed by the Essentials of Magnetism II (EOMII) and the Nursing Work Index-Revised (NWI-R) were reported (Jones, 2014; Schubert et al., 2007; Schubert et al., 2008).

Process measures are valid quality indicators only when they are plausibly related to important outcomes (Donabedian, 2003). In addition to the previously described associations with adverse patient outcomes, evidence of relationships between UNC and the following outcomes (Table 3) also is documented: patient satisfaction (Ausserhofer et al., 2013; Schubert et al., 2007), overall quality of care (Ball, et al., 2013; Jones, 2014; Sochalski, 2004), nurse job satisfaction (Jones, 2014), nurse occupational satisfaction (Kalisch, Tschannen, \& Lee, 2011), turnover, and intent to leave (Tschannen, Kalisch, \& Lee, 2010). These relationships support UNC as a valid indicator of patient care quality and an important precursor to adverse outcomes. 
UNC instruments demonstrated high reliability. Reported Cronbach alphas ranged from .73 to .97 (Ausserhofer et al., 2013; Castner, et al., 2014; Cho et al., 2015; Jones, 2014; Kalisch \& Williams, 2009; Lucero et al., 2009; Nelson \& Flynn, 2015; Rochefort \& Clarke, 2010; Schubert et al., 2007). These findings were comparable to reported reliability coefficients (.71 to .84) for another NQF-endorsed survey measure, the Practice Environment Scale-Nursing Work Index (PES-NWI; Lake, 2002).

One limitation to the science of UNC that may influence the scientific acceptability of UNC as a performance indicator is the threat of common method/source bias. Current measures of UNC rely on nurse self-report and none were validated against the presumed gold standard of direct observation or nursing documentation systems. Similarly, many of the studies linking UNC to patient outcomes were based on nurse-reported outcome frequency (Ausserhoffer et al., 2013; Ball et al., 2014; Kalisch et al., 2011; Lucero et al., 2010; Schubert et al., 2009; Sochalski, 2004). However, both mortality and readmissions have been linked to UNC using objective independent data sources (Brooks Carthon et al., 2015; Schubert et al., 2012). Although additional validation studies that incorporate independent data sources might further strengthen the perceived scientific acceptability, their absence should not be interpreted as a significant limitation. Direct care nurses ultimately accomplish the transformation of resources into nursing services. Nurse reports of patient care quality are increasingly recognized as valid quality indicators (McHugh \& Stimpfel, 2012). Moreover, cognitive aspects of nursing processes may be difficult to detect during direct observation and elements of completed nursing care may not always be documented (Needleman, Kurtzman, \& Kizer, 2007). Therefore, direct care nurses are arguably the best source of information about UNC. Notably, the use of common method/source bias also pertains to the PES-NWI, which also was validated based on associations with nurse- 
reported outcomes (Hanrahan, Aiken, McClaine, \& Hanlon, 2010; McHugh \& Stimpfel, 2012; Van Bogaert, Clarke, Vermeyen, Meulemans, \& Van de Heyning, 2008).

Another potential limitation to the perceived scientific acceptability of UNC is the hospitalcentric nature of the existing body of evidence. Although most available evidence about UNC pertains to nursing care in acute care hospitals (Papastavrou et al., 2014), UNC is not a hospitalcentric indicator. UNC is relevant to patients and nurses across the care continuum. Adaptation of the currently available instruments to assess UNC in other practice settings is quite feasible. Preliminary work to adapt these instruments for long-term care facilities (Nelson \& Flynn, 2015), the operating room (Kalisch, 2015, pp. 129-135), and neonatal intensive care (Rochefort \& Clarke, 2010; Tubbs-Cooley, Pickler, Younger, \& Mark, 2015) are already underway. The prevalence of UNC in these practice settings (reported by $20-50 \%$ of nurses surveyed) was lower than hospital adult inpatient areas but still significant.

\section{Usability}

Useable performance measures produce information that is understandable and useful for decision-making among stakeholders (NQF, 2004). UNC is a highly useful performance measure because of the juxtaposition between numerous malleable antecedents and important quality outcomes. The previously described role of UNC as a precursor to adverse outcomes makes UNC an important risk factor. Early identification of this risk factor provides an opportunity for intervention before serious adverse outcomes materialize (Ball et al., 2014; Bittner, Gravlin, Hansten, \& Kalisch, 2011; Kalisch, 2015).

Information about UNC can be reported in formats that are easy to understand for all stakeholders. Prevalence estimates of UNC are derived from self-report surveys using simple descriptive statistics to include: the mean frequency of UNC; percent of nurses that leave any 
activity unfinished; and the mean number of activities left unfinished (Jones, Gemeinhardt, Thompson, \& Hamilton, 2015a). UNC surveys address nursing processes that are meaningful and relevant for every patient and every nurse (Aiken et al., 2001; Kalisch \& Williams, 2009; Schubert et al., 2007). Moreover, interpretation of UNC estimates do not require advanced knowledge of disease processes, treatment modalities, risk stratification, or coding procedures. Aggregate prevalence estimates at the unit and organization level provide useful information about how often the condition of time scarcity is experienced, which reflects the adequacy and stability of staffing and workflow processes (Jones et al., 2015b). Item level prevalence estimates provide useful information about how nurses prioritize, which can be used to anticipate specific areas of vulnerability. For example, patterns that indicate more frequent UNC in the area of discharge planning indicate a vulnerability to preventable readmissions.

Potential avenues for intervention and prevention involve mitigating conditions that produce time scarcity. The condition of time scarcity that precipitates UNC is conceived as the end result of multiple interdependent decisions made at the macro and meso level of the healthcare system (Jones et al., 2015b; Schubert et al., 2007). Macro level decisions by policy makers and payors affect revenue streams for organizations and providers. Revenue streams in turn affect decision making at the meso level as administrators and frontline managers struggle to constrain costs. This can result in budgetary decisions that negatively affect the allocation and deployment of nursing resources, which create conditions of time scarcity.

The condition of time scarcity also may be affected by decisions related to care team interactions. Poorly sequenced workflows and disruptive team behaviors such as interruptions and poor communication contribute to system inefficiencies (Jones \& Yoder, 2014; Kalisch \& Lee, 2010). Inefficiencies increase time consumption for some activities creating conditions of 
time scarcity for others. A growing body of evidence supports many of these presumed relationships. Specifically, the following antecedents are significantly associated with UNC: decreased nurse staffing (increased patient to nurse ratios and hours of care per patient day), a weak patient safety culture, poor team communication and teamwork, and unpredictable workloads (Al-Kandari \& Thomas, 2009; Ausserhofer et al., 2013; Ball et al., 2013; Cho et al., 2015; Kalisch \& Lee, 2010; Nelson \& Flynn, 2015; Rochefort \& Clarke, 2010; Schubert et al., 2007; Schubert et al., 2008; Tubbs-Cooley et al., 2015). Therefore, higher levels of UNC will direct stakeholders to re-evaluate decisions related to reimbursement policies, organizational operating budgets, human resource policies, nurse staffing practices, care delivery and professional practice models, team training, and workflow design.

The relationship to multiple dimensions of the healthcare delivery system make UNC an important and useful balancing measure that can help identify and minimize potential metricdriven harm. For example, tunnel vision is one type of metric-driven harm reported in nursing services (Rambur et al., 2013). Patterns of UNC suggest that nurses prioritize elements of care that are most likely to be audited and/or are financially incentivized (e.g. elements of care bundles) over other equally important aspects of care such as teaching and emotional support (Jones et al., 2015b; Rambur et al., 2013). More intense auditing is expected to accompany the anticipated expansion of value-based purchasing initiatives to more nurse sensitive outcomes (Kavanaugh et al., 2012). Consequently, patients will be increasingly vulnerable to the underuse of beneficial but unmeasured elements of nursing care. Prioritization of care based on audited metrics and financial incentives rather than patient needs is inconsistent with the aims of patient centered care (IOM, 2001). Moreover, some patient populations may be more vulnerable to the effects of these prioritization practices. For example, the effects of underuse in the area of patient 
teaching may be more severe for patients with low health literacy and multiple complex comorbid conditions. Therefore, these practices may result in care that is not equitable. Ongoing analysis of the patterns of UNC and innovative intervention strategies will become increasingly important to detect prioritization practices inconsistent with the aims for patient centered and equitable care and to prevent the underuse of beneficial nursing services that are not audited or financially incentivized.

Nursing services also are vulnerable to measure fixation (Rambur et al., 2013). Declining reimbursement creates a preoccupation with financial and productivity measures in many organizations. This form of measure fixation increases the potential that administrators will prioritize meeting productivity targets over all other performance activities (Jones et al., 2015b). Traditional measures of productivity are expressed as an estimate of the number of staff needed to care for a given patient volume and/or acuity divided by the actual number of staff delivering care. Productivity targets are considered met when the actual number of staff delivering care is at or below the predicted estimates. This approach to measuring productivity does not reflect the actual amount of care produced relative to the amount of care needed. Therefore, strict adherence to productivity targets does not always result in an optimal balance between the supply and demand for nursing care and can induce harm to patients and nurses related to inadequate staffing and excessive workload (Jones \& Yoder, 2010).

Intuitively, fixation on productivity and financial measures is more likely to occur when other important performance indicators are not explicitly and routinely measured, publicly reported, endorsed by regulatory bodies, and/or financially incentivized (Adair et al., 2006; Rambur et al., 2013). UNC reflects the balance between the demand for and production of nursing services and is arguably the most relevant measure of productivity and staffing 
effectiveness. In fact, UNC is a stronger predictor of adverse patient outcomes than nurse staffing indices (Schubert et al., 2008). Therefore, endorsement of UNC as a nurse sensitive performance indicator represents an important strategy to mitigate the risk of harm associated with the current preoccupation on productivity and efficiency.

One potential limitation to the usefulness of UNC relates to instrument bias. Although different instruments yield moderately concordant estimates of UNC $($ kappa $=.510 ; p<.001)$, identified sources of bias pose challenges for comparing UNC estimates across instruments (Jones et al., 2015b). Prevalence estimates are influenced by the following instrument characteristics: inventory size, scope and specificity, scoring procedures, and scope of response options. Each instrument has identified strengths and no instrument is yet identified as superior. More research is needed to guide interpretation of UNC estimates across instruments or alternatively to determine which instrument is best suited for endorsement.

\section{Feasibility}

Feasible measures are defined as those that provide enough benefit to the stakeholders to outweigh the costs and burden of data collection (NQF, 2004). Feasibility is enhanced when measures can be collected at or near the point of care delivery and within the normal flow of care delivery. The process of acquiring UNC estimates from nurse self-report places data collection near the point of care but is external to normal workflows. Further, surveys can be expensive and nurses are often resistant to increased burdens on their time (Needleman et al., 2007). This may result in low survey response rates, which ultimately affect the validity and usefulness of the data. Additional considerations for the feasibility of collecting data about UNC are related to the sensitive nature of the data. Nurses may hesitate to report UNC for fear of retribution from 
employers. Moreover, administrators may be reluctant to document the prevalence of UNC for legal reasons as well as for fear of tarnishing the organizational reputation.

Data collection for performance monitoring is never cost neutral or risk free. However, O'Brien et al. (2012) assert that "if a measure addresses an important topic, has been specified in a way that is scientifically acceptable and produces useful results, all efforts should be made to acquire the necessary information to make implementation feasible" (pp. 303). The importance and usability of UNC information warrant an investment in data collection. The cost of staff surveys is negligible compared to the costs of record abstraction required for other performance measures (Romano, Hussey, \& Ritley, 2010). Staff survey burden is a function of the size of the survey and frequency of administration. UNC surveys range in size from 5 (Zhu et al., 2012) to 52 (Rochefort \& Clarke, 2010) items, which is comparable to the endorsed PES-NWI (31; Lake, 2002). The recommended frequency of administration is related to assumptions about patterns of variation and organizational context. Annual assessment may be sufficient in stable environments with a low prevalence of UNC and adverse outcomes. However, cyclic variations in patient volumes and/or staff supply occur in some organizations. Annual assessment would be insufficient to capture this variation and would result in inaccurate estimates of UNC (Alexander, 2007). More frequent assessment also is indicated in the setting of suboptimal patient outcomes or in the midst of unstable processes and organizational changes likely to affect conditions of time scarcity. Therefore, an initial period of frequent assessment, perhaps monthly, is recommended to identify patterns of variation (e.g. common versus special cause) and stability of related processes (Polit \& Chaboyer, 2012). After establishing baseline data related to UNC patterns in an organization, quarterly assessments of UNC can be a useful surveillance tool. 
Staff willingness to complete surveys is related to perceived relevance, usefulness, and confidentiality. Issues related to staffing and the ability to provide quality patient care are important to staff nurses (Aiken, Clarke, Sloane, Lake, \& Cheney, 2008; Kalisch, Tschannen, \& Lee, 2011). However, when nurses perceive that data are not used to improve their work environment or patient care, they may grow weary of completing surveys. Therefore, feedback of survey findings and subsequent improvement initiatives are needed to enhance feasibility of sustained data collection. The feasibility of reporting and disclosing information about UNC can be enhanced through creation of cultures of safety (Weaver et al., 2013). Healthcare systems that encourage an open dialogue about safety concerns without fear of reprisal may find nurses investing their time in safety-related surveys.

Procedures to protect confidentiality also are warranted. Protocols already exist for NDNQI survey data, which could be adapted for UNC data. For example, individual results are never reported and data from units with low sample sizes are included in the organization level analysis but not reported at the unit level (Polit \& Chaboyer, 2012).

\section{Conclusions and Implications}

Performance measurement is essential for quality improvement in nursing. Because of the gaps in the current measure set, the American Academy of Nursing has called for more nursing performance measurement research (Lamb \& Donaldson, 2011). Nursing processes represent important mechanisms in the transformation of nursing resources into changes in patients' conditions. However, measures of nursing processes and the underuse of nursing services are underrepresented in the endorsed measure set and in national performance measurement initiatives. Measures of UNC address these identified gaps in performance measurement for nursing. UNC is an important performance measure for nursing care systems that warrants 
continued development and refinemet. Current evidence regarding the importance, scientific acceptability, usefulness, and feasibility of UNC as a performance measure is compelling. Continued research will help to better define the relationship between UNC and changes in patient conditions while also refining the measure to further limit concerns for common method/source bias. Continued UNC research should include expansion to new patient care settings with an emphasis on minimizing the data collection burden in all settings. Inclusion of UNC in performance measurement systems may result in innovative improvement initiatives and the allocation of resources needed to deliver the right care to the right patient at the right time. 


\section{References}

Adair, C. E., Simpson, E., Casebeer, A. L., Birdsell, J. M., Hayden, K. A., \& Lewis, S. (2006). Performance measurement in healthcare: Part II - state of the science findings by stage of the performance measurement process. Healthcare Policy, 2(1), 56-78.

Agency for Healthcare Research and Quality. (2015a). 2014 national healthcare quality and disparities report (AHRQ Publication No. 15-0007). Retrieved from http://www.ahrq.gov/research/findings/nhqrdr/index.html

Agency for Healthcare Research and Quality. (2015b). Patient safety primer: Missed nursing care. [Online resource]. Retrieved from http://psnet.ahrq.gov/primer.aspx?primerID=29

Agency for Healthcare Research and Quality. (2015c). Inpatient quality indicators technical specifications - version 5.0, March 2015. Retrieved from http://www.qualityindicators.ahrq.gov/Modules/IQI_TechSpec.aspx

Agency for Healthcare Research and Quality. (2015d). Patient safety indicators technical specifications updates - version 5.0 (IDC 10), October 2015. Retrieved from http://www.qualityindicators.ahrq.gov/Modules/PSI_TechSpec_ICD10.aspx

Agency for Healthcare Research and Quality. (2015e). Quality indicator overview. Retrieved from http://www.qualityindicators.ahrq.gov/FAQs_Support/FAQ_QI_Overview.aspx

Aiken, L. H., Clarke, S. P., Sloane, D. M., Lake, E., \& Cheney, T. (2008). Effects of hospital care environment on patient mortality and nurse outcomes. Journal of Nursing Administration, $38(5), 223-229$.

Aiken, L. H., Clarke, S. P., Sloane, D. M., Sochalski, J. A., Busse, R., Clarke, H.,... Shamian, J. (2001). Nurses' reports on hospital care in five countries. Health Affairs, 20(3), 43-53. doi:10.1377?hlthaff.20.3.43 
Al-Kandari, F., \& Thomas, D. (2009). Factors contributing to nursing task incompletion as perceived by nurses working in Kuwait general hospitals. Journal of Clinical Nursing, 18(24), 3430-3440. doi:10.1111/j.1365-2702.2009.02795.x

Alexander, G. R. (2007). Nursing sensitive databases: Their existence, challenges, and importance. Medical Care Research and Review, 64(2 Suppl), 44S-63S. doi:10.1177/1077558707299244

Ausserhofer, D., Schubert, M., Desmedt, M., Blegen, M. A., De Geest, S., \& Schwendimann, R. (2013). The association of patient safety climate and nurse-related organizational factors with selected patient outcomes: A cross-sectional survey. International Journal of Nursing Studies, 50(2), 240-252. doi:10.1016/j.ijnurstu.2012.04.007

Ausserhofer, D., Zander, B., Busse, R., Schubert, M., De Geest, S., Rafferty, A. M.,...consortium, RN CAST. (2014). Prevalence, patterns and predictors of nursing care left undone in European hospitals: Results from the multicountry cross-sectional RN4CAST study. BMJ Quality and Safety, 23(2), 126-135. doi:10.1136/bmjqs-2013-002318

Ball, J. E., Murrells, T., Rafferty, A. M., Morrow, E., \& Griffiths, P. (2014). 'Care left undone' during nursing shifts: Associations with workload and perceived quality of care. $B M J$ Quality and Safety, 23(2), 116-125. doi:10.1136/bmjqs-2012-001767

Bittner, N. P., Gravlin, G., Hansten, R., \& Kalisch, B. J. (2011). Unraveling care omissions. Journal of Nursing Administration, 41(12), 510-512.

doi:10.1097/NNA.0b013e3182378b65

Blegen, M. A., Goode, C. J., Spetz, J., Vaughn, T., \& Park, S. H. (2011). Nurse staffing effects on patient outcomes: Safety-net and non-safety-net hospitals. Medical Care, 49(4), 406-414. 
Brooks Carthon, J. M., Lasater, K. B., Sloane, D. M., \& Kutney-Lee, A. (2015). The quality of hospital work environments and missed nursing care is linked to heart failure readmissions: A cross-sectional study of US hospitals. BMJ Quality and Safety, 24, 255-263.

Brown, D. S., Donaldson, N., Bolton, L. B., \& Aydin, C. E. (2010). Nursing-sensitive benchmarks for hospitals to gauge high-reliability performance. Journal for Healthcare Quality, 32(6), 9-17.

Castner, J., Wu, Y. W., \& Dean-Baar, S. (2014). Multi-level model of missed nursing care in the context of hospital merger. Western Journal of Nursing Research, 37(4), 441-461. doi:10.1177/0193945914535670

Centers for Disease Control and Prevention. (2015). National Healthcare Safety Network overview. Retrieved from http://www.cdc.gov/nhsn/pdfs/pscmanual/pcsmanual_current.pdf Center for Medicare \& Medicaid Services. (2015a). Hospital compare. Retrieved from http://www.medicare.gov/hospitalcompare/search.html

Center for Medicare \& Medicaid Services. (2015b). Measure comparison (inpatient hospital quality measures). Retrieved from https://www.qualitynet.org/dcs/ContentServer?c=Page\&pagename=QnetPublic\%2FPage $\%$ 2FQnetTier3\&cid=1138900298473

Chassin, M. R., \& Loeb, J. M. (2013). High reliability health care: Getting there from here. The Milbank Quarterly, 91(3), 459-490.

Chassin, M. R., Loeb, J. M., Schmaltz, S. P., \& Wachter, R. M. (2010). Accountability measures--using measurement to promote quality improvement. New England Journal of Medicine, 363(7), 683-688. doi:10.1056/NEJMsb1002320 
Cho, S. H., Kim, Y. S., Yeon, K. N., You, S. J., \& Lee, I. D. (2015). Effects of increasing nurse staffing on missed nursing care. International Nursing Review, 62(2), 267-274. doi:10.1111/inr.12173

Clarke, S. P. (2015). Evaluating policy structures, processes, and outcomes. In R. Patton, M. Zalon, \& R. Ludwick (Eds.), Nurses making policy: From bedside to boardroom (p. 433468). New York, NY: Springer.

Collins, B. (2009). VA Nursing Outcomes Database and the clinical nurse leader. [slide show] Retrieved from http://www.slideshare.net/datacenters/office-of-nursing-services-vanursing-outcomes-database-vanod?from_action=save

Donabedian, A. (2003). An introduction to quality assurance in health care. New York, NY: Oxford University Press.

Dubois, C. A., D’Amour, D., Pomey, M. R., Girard, F., \& Brault, I. (2013). Conceptualizing performance of nursing care as a prerequisite for better measurement: A systematic and interpretive review. BMC Nursing, 12(7), 1-20. Retrieved from http://www.biomedcentral.com/1472-6955/12/7

Elg, M., Broryd, K. P., \& Kollberg, B. (2013). Performance measurement to drive improvements in healthcare practice. International Journal of Operations \& Production Management, 33(11/12), 1623-1651. doi:10.1108/IJOPM-07-2010-0208

Gajewski, B. J., Lee, R., \& Dunton, N. (2012). Data envelopment analysis in the presence of measurement error: Case study from the National Database of Nursing Quality Indicators(R) (NDNQI(R)). Journal of Applied Statistics, 39(12), 2639-2653. doi:10.1080/02664763.2012.724664 
Hanrahan, N. P., Aiken, L. H., McClaine,L., \& Hanlon, A. L. (2010). Relationships between psychiatric nurse work environments and nurse burnout in acute care general hospitals. Issues in Mental Health Nursing, 31, 198-207.

Institute of Medicine. (1999). To err is human: Building a safer health system (L. T. Kohn, J. Corrigan, \& M. S. Donaldson, Eds.). Washington, D.C.: National Academy Press. Institute of Medicine. (2001). Crossing the quality chasm: A new health system for the $21^{\text {st }}$ Century. Washington, DC: National Academies Press.

Institute of Medicine. (2003). Priority areas for national action: Transforming health care quality (K. Adams \& J. M. Corrigan, Eds.). Washington, D.C.: National Academies Press. Institute of Medicine. (2004). Keeping patients safe: Transforming the work environment of nurses (A. Page, Ed.). Washington, D.C.: National Academies Press.

Institute of Medicine. (2006). Performance measurement: Accelerating improvement. Washington, D.C.: National Academies Press.

Institute of Medicine. (2013). Best care at lower cost: The path to continuously learning health care in America (M. Smith, R. Saunders, L. Stuckhardt, \& J. M. McGinnis, Eds.). Washington, D.C.: National Academies Press.

Jones, T. L. (2014). Validation of the Perceived Implicit Rationing of Nursing Care (PIRNCA) instrument. Nursing Forum, 49(2), 77-87. doi:10.1111/nuf.12076

Jones, T. L. (2015). A descriptive analysis of implicit rationing of nursing care: Frequency and patterns in Texas. Nursing Economic\$, 33(3), 144-154.

Jones, T. L., Gemeinhardt, G., Thompson, J. A., \& Hamilton, P. (2015a). Measuring unfinished nursing care: What to consider when choosing and scoring surveys. Journal of Nursing Care Quality. doi:10.1097/NCQ0000000000000143 
Jones, T. L., Hamilton, P., \& Murry, N. (2015b). Unfinished nursing care, missed care, and implicitly rationed care: State of the science review. International Journal of Nursing Studies, 52(6), 1121-1137. http://dx.doi.org/10.1016/j.ijnurstu.2015.02.012

Jones, T. L., \& Yoder, L. (2010). Economic theory and nursing administration research--is this a good combination? Nursing Forum, 45(1), 40-53. doi:10.1111/j.1744-6198.2009.00160.x

Jones, T. L., \& Yoder, L. H. (2014). Dimensions of nurse work time: Progress in instrumentation. Nursing \& Health Sciences. doi:10.1111/nhs.12191

Kalisch, B. J. (2006). Missed nursing care: A qualitative study. Journal of Nursing Care Quality, 21(4), 306-313, quiz 314-305.

Kalisch, B. J. (2015). Errors of omission: How missed nursing care imperils patients. Silver Springs, MD: American Nurses Association.

Kalisch, B. J., Gosselin, K., \& Choi, S. H. (2012). A comparison of patient care units with high versus low levels of missed nursing care. Health Care Management Review, 37(4), 320-328. doi:10.1097/HMR.0b013e318249727e

Kalisch, B. J., \& Lee, K. H. (2010). The impact of teamwork on missed nursing care. Nursing Outlook, 58(5), 233-241. doi:10.1016/j.outlook.2010.06.004

Kalisch, B. J., \& Lee, K. H. (2012). Missed nursing care: Magnet versus non-Magnet hospitals. Nursing Outlook, 60(5), e32-39. doi:10.1016/j.outlook.2012.04.006

Kalisch, B. J., Tschannen, D., \& Lee, H. (2011). Does missed nursing care predict job satisfaction? Journal of Healthcare Management, 56(2), 117-133.

Kalisch, B. J., Tschannen, D., \& Lee, H. (2012). Missed nursing care, staffing, and patient falls. Journal of Nursing Care Quality, 27(1), 6-12. 
Kalisch, B. J., Tschannen, D., Lee, H., \& Friese, C. R. (2011). Hospital variation in missed nursing care. American Journal of Medical Quality, 26(4), 291-299. doi:10.1177/1062860610395929

Kalisch, B. J., \& Williams, R. A. (2009). Development and psychometric testing of a tool to measure missed nursing care. The Journal of Nursing Administration, 39(5), 211-219. doi:10.197/NNA.0b013e3181a23cf5

Kane, R. L., Shamliyan, T. A., Mueller, C., Duval, S., \& Wilt, T. J. (2007). The association of registered nurse staffing levels and patient outcomes: Systematic review and meta-analysis. Medical Care, 45(12), 1195-1204.

Kavanagh, K. T., Cimiotti, J. P., Abusalem, S., \& Coty, M. B. (2012). Moving healthcare quality forward with nursing-sensitive value-based purchasing. Journal of Nursing Scholarship, 44(4), 385-395. doi:10.1111/j.1547-5069.2012.01469.x

Kutney-Lee, A., Brennan, C. W., Meterko, M., \& Ersek, M. (2015). Organization of nursing and quality of care for veterans at the end of life. Journal of Pain Symptom Management, 49(3), 570-577. doi:10.1016/j.jpainsymman.2014.07.002

Kurtzman, E. T., Dawson, E. M., \& Johnson, J. E. (2008). The current state of nursing performance measurement, public reporting, and value-based purchasing. Policy, Politics \& Nursing Practice, 9(3), 181-191.

Lake, E. T. (2002). Development of the Practice Environment Scale of the Nursing Work Index. Research in Nursing \& Health, 25(3), 176-188. doi:10.1002/nur.10032

Lamb, G., \& Donaldson, N. (2011). Performance measurement - a strategic imperative and a call to action. Nursing Outlook, 59, 336-338. 
Lucero, R. J., Lake, E. T., \& Aiken, L. H. (2009). Variations in nursing care quality across hospitals. Journal of Advanced Nursing, 65(11), 2299-2310. doi:10.1111/j.13652648.2009.05090.x

Lucero, R. J., Lake, E. T., \& Aiken, L. H. (2010). Nursing care quality and adverse events in US hospitals. Journal of Clinical Nursing, 19(15-16), 2185-2195. doi:10.1111/j.13652702.2010.03250.x

Mannion, R., \& Braithwaite, J. (2012). Unintended consequences of performance measurement in healthcare: 20 salutary lessons from the English National Health Service. Internal Medicine Journal, 42(5), 569-574. doi:10.1111/j.1445-5994.2012.02766.x

McHugh, M. D., \& Stimpfel, A. W. (2012). Nurse reported quality of care: A measure of hospital quality. Research in Nursing \& Health, 35, 566-575.

Montalvo, I. (2007). The National Database of Nursing Quality Indicators (NDNQI). OJIN: The Online Journal of Issues in Nursing, 12(3), manuscript 2. doi:10.3912/OJIN.Vol12No03Man02

National Priorities Partnership. (2008). Aligning our efforts to transform America's healthcare: National priorities \& goals. Washington, D.C.: National Quality Forum.

National Quality Forum. (2015). National Quality Forum endorsed standards. Retrieved from http://www.qualityforum.org/measures_list.aspx

National Quality Forum. (2004). National voluntary consensus standards for nursing-sensitive care: An initial performance measure set. A consensus report. Washington, DC: National Quality Forum. 
Naylor, M. D. (2007). Advancing the science in the measurement of health care quality influenced by nurses. Medical Care Research and Review, 64(2 Suppl), 144S-169S. doi:10.1177/1077558707299257

Needleman, J., Buerhaus, P., Mattke, S., Stewart, M., \& Zelevinsky, K. (2002). Nursing staffing levels and the quality of care in hospitals. New England Journal of Medicine, 364(11), $1715-1722$.

Needleman, J., Kurtzman, E. T., \& Kizer, K. W. (2007). Performance measurement of nursing care: State of the science and the current consensus. Medical Care Research and Review, 64(2), 10S-43S.

Nelson, S. T., \& Flynn, L. (2015). Relationship between missed care and urinary tract infections in nursing homes. Geriatric Nursing, 36(2), 126-130. doi:10.1016/j.gerinurse.2014.12.009

O’Brien, J. M., Corrigan, J., Reitzner, J. B., Moores, L. K., Metersky, M., Hyzy, R. C., . . Pace, K. (2012). Will performance measurement lead to better patient outcomes? What are the roles of the National Quality Forum and medical specialty societies? Chest, 141(2), 300307. doi:10.1378/chest.11-1942

Papastavrou, E., Andreou, P., \& Efstathiou, G. (2014). Rationing of nursing care and nursepatient outcomes: A systematic review of quantitative studies. International Journal of Health Planning and Management, 29(1), 3-25. doi:10.1002/hpm.2160

Patrician, P. A., Loan, L., McCarthy, M., Brosch, L. R., \& Davey, K. S. (2010). Towards evidence-based management: Creating an informative database of nursing-sensitive indicators. Journal of Nursing Scholarship, 42(4), 358-366.

doi:10.1111/j.1547-5069.2010.01364.x 
Perlin, J., Horner, S. J., Englebright, J. D., \& Bracken, R. M. (2012). Rapid core measure improvement through a "business case for quality.” Journal for Healthcare Quality, 36(2), 50-61.

Polit, D. F., \& Chaboyer, W. (2012). Statistical process control in nursing research. Research in Nursing \& Health, 35, 82-93.

Powell, A. A., White, K. M., Partin, M. R., Halek, K., Christianson, J. B., Neil, B.,...Bloomfield, H. E. (2012). Unintended consequences of implementing a national performance measurement system into local practice. Journal of General Internal Medicine, 27(4), 405412. doi:10.1007/s11606-011-1906-3

Quraishi, J., \& Jordan, L. (2014). Quality and performance measurement: National efforts to improve quality of care through measurement development. AANA Journal, 82(3), 184-187.

Rambur, B., Vallett, C., Cohen, J. A., \& Tarule, J. M. (2013). Metric-driven harm: An exploration of unintended consequences of performance measurement. Applied Nursing Research, 26, 269-272. doi:10.1016/j.apnr.2013.09.001

Rochefort, C. M., \& Clarke, S. P. (2010). Nurses' work environments, care rationing, job outcomes, and quality of care on neonatal units. Journal of Advanced Nursing, 66(10), 2213-2224. doi:10.1111/j.1365-2648.2010.05376x

Romano, R., Hussey, P., \& Ritley, D. (2010). Selecting quality and resource use measures: A decision guide for community quality collaboratives (Report No. 09(10)-0073. Rockville, MD: Agency for Healthcare Research and Quality.

Schubert, M., Ausserhofer, D., Desmedt, M., Schwendimann, R., Lesaffre, E., Li, B., \& De Geest, S. (2013). Levels and correlates of implicit rationing of nursing care in Swiss acute 
care hospitals--a cross sectional study. International Journal of Nursing Studies, 50(2), 230-239. doi:10.1016/j.ijnurstu.2012.09.016

Schubert, M., Clarke, S. P., Aiken, L. H., \& De Geest, S. (2012). Associations between rationing of nursing care and inpatient mortality in Swiss hospitals. International Journal for Quality in Healthcare, 24(3), 230-238.

Schubert, M., Clarke, S. P., Glass, T. R., Schaffert-Witvliet, B., \& De Geest, S. (2009). Identifying thresholds for relationships between impacts of rationing of nursing care and nurse- and patient-reported outcomes in Swiss hospitals: A correlational study. International Journal of Nursing Studies, 46(7), 884-893.

Schubert, M., Glass, T. R., Clarke, S. P., Aiken, L. H., Schaffert-Witvliet, B., Sloane, D. M., \& De Geest, S. (2008). Rationing of nursing care and its relationship to patient outcomes: The Swiss extension of the International Hospital Outcomes Study. International Journal for Quality in Health Care, 20(4), 227-237. doi:10.1093/intqhc/mzn017

Schubert, M., Glass, T. R., Clarke, S. P., Schaffert-Witvliet, B., \& De Geest, S. (2007). Validation of the Basel Extent of Rationing of Nursing Care instrument. Nursing Research, 56(6), 416-424.

Schuster, M. A., McGlynn, E. A., \& Brook, R. H. (2005). How good is the quality of health care in the United States? Milbank Quarterly, 83(4), 843-895.

doi:10.1111/j.1468-0009.2005.00403.x

Sochalski, J. (2004). Is more better? The relationship between nurse staffing and the quality of nursing care in hospitals. Medical Care, 42(2), II-67-II-73.

Smith, P. (1995). On the unintended consequences of publishing performance data in the public sector. International Journal of Public Administration, 18(2-3), 277-310. 
The Joint Commission. (2015a). America's hospitals: Improving quality and safety - The Joint Commission's Annual Report 2014. Retrieved from http://www.jointcommission.org/assets/1/18/TJC_Annual_Report_2015_EMBARGOED_1 1_9_15.pdf

The Joint Commission. (2015b). Core measure sets. Retrieved from http://www.jointcommission.org/core_measure_sets.aspx

The Joint Commission. (2015c). 2015 specifications manual for Joint Commission national quality core measures. Retrieved from https://manual.jointcommission.org/releases /TJC2015A1/rsrc/Manual/TableOfContentsTJC/TJC_v2015A1.pdf?rev=9Jan2015

The Joint Commission. (2015d). National patient safety goals effective January 1, 2016. Retrieved from http://www.jointcommission.org/assets/1/6/2016_NPSG_HAP.pdf

Tschannen, D., Kalisch, B. J., \& Lee, K. H. (2010). Missed nursing care: The impact on intention to leave and turnover. The Canadian Journal of Nursing Research, 42(2), 22-39.

Tubbs-Cooley, H. L., Pickler, R. H., Younger, J. B., \& Mark, B. A. (2015). A descriptive study of nurse-reported missed care in neonatal intensive care units. Journal of Advanced Nursing, 71(4), 813-824. doi:10.1111/jan.12578

U.S. Department of Health and Human Services. (2011). Report to Congress: National strategy for quality improvement in health care. Washington, DC: U.S. Department of Health and Human Services. Retrieved from http://www.ahrq.gov/workingforquality/nqs/nqs2011annlrpt.pdf

U.S. Department of Labor, Bureau of Labor Statistics. (2013). Employment projections: Employment by detailed occupation [Data file]. Retrieved from http://www.bls.gov/emp/ep_table_102.htm 
U.S. Department of Veterans Affairs. (2010). History: VA nursing - A profession and passion. Retrieved from http://www.va.gov/nursing/docs/about/historyvansg2010.doc

Van Bogaert, P., Clarke, S., Vermeyen, K., Meulemans, H., \& Van de Heyning, P. (2008).

Practice environments and their associations with nurse-reported outcomes in Belgian hospitals: Development and preliminary validation of a Dutch adaptation of the Revised Nursing Work Index. International Journal of Nursing Studies, 46(1), 55-65.

Wachter, R. M. (2010). Patient safety at ten: Unmistakable progress, troubling gaps. Health Affairs (Millwood), 29(1), 165-173. doi:10.1377/hlthaff.2009.0785

Weaver, S. J., Lubomski, L. H., Wilson, R. F., Pfoh, E. R., Martinez, K. A., \& Dy, S. M. (2013). Promoting a culture of safety as a patient safety strategy: A systematic review. Annals of Internal Medicine, 158(5), 369-374.

Zhu, X. W., You, L. M., Zheng, J., Liu, K., Fang, J. B., Hou, S. X.,... Zhang, L. F. (2012). Nurse staffing levels make a difference on patient outcomes: A multisite study in Chinese hospitals. Journal of Nursing Scholarship, 44(3), 266-273.

doi:10.1111/j.15475069.2012.01454.x 
Table 1

Nursing-Sensitive Care Indicators Endorsed by the National Quality Forum

Framework Category

Patient-centered outcomes measures
Failure to rescue (death among surgical inpatients with treatable serious complications)

Pressure ulcer prevalence

Falls prevalence

Falls with injury

Restraint prevalence

Urinary catheter-associated urinary tract infection for ICU patients

Central line catheter-associated blood stream infection rate for ICU and HRN patients

Ventilator-associated pneumonia for ICU and HRN patients
Nursing-centered intervention measures
Smoking cessation counseling for acute myocardial infarction

Smoking cessation counseling for heart failure

Smoking cessation counseling for pneumonia

System-centered measures

Skill mix (RN, LVN/LPN, UAP, and contract)

Nursing care hours per patient day (RN, LVN/LPN, UAP)

Practice Environment Scale - Nursing Work Index (composite and five subscales)

Voluntary turnover

Note. HRN = high-risk nursery; ICU = intensive care unit; LPN = licensed practical nurse;

$\mathrm{LVN}=$ licensed vocational nurse $; \mathrm{RN}=$ registered nurse; UAP = unlicensed assistive personnel.

Adapted from National Quality Forum, 2004, National Voluntary Consensus Standards for

Nursing-Sensitive Care: An Initial Performance Measure Set. A Consensus Report, p. VI.

Reused with permission. Copyright 2015 by the National Quality Forum. 
Table 2

Inclusion of Nurse-Sensitive Indicators in Performance Measurement Programs

\begin{tabular}{|c|c|c|c|c|c|c|c|c|}
\hline & 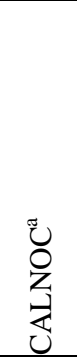 & 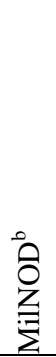 & 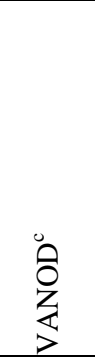 & $\begin{array}{l}\bar{\sigma} \\
\bar{z} \\
\bar{z}\end{array}$ & 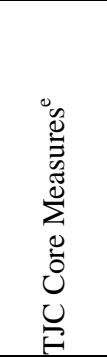 & 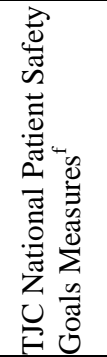 & 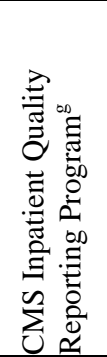 & 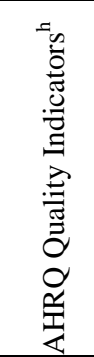 \\
\hline Number of Contributing Hospitals & 225 & 13 & $\sim 114$ & $>1800$ & $>3300$ & $>3300$ & $>4000$ & $>4000$ \\
\hline Total Number of Indicators & 11 & 17 & 12 & 18 & 40 & 35 & 69 & 101 \\
\hline $\begin{array}{l}\text { Total Number of Endorsed Nurse Sensitive Indicators } \\
\text { Included }\end{array}$ & 5 & 7 & 6 & 10 & 3 & 2 & 3 & 3 \\
\hline - $\quad$ Failure to rescue & & & & & & & $\mathrm{X}$ & $\mathrm{X}$ \\
\hline - $\quad$ Pressure ulcer prevalence & & $\mathrm{X}$ & $\mathrm{X}$ & $\mathrm{X}$ & & & & $\mathrm{X}$ \\
\hline - $\quad$ Falls prevalence & $\mathrm{X}$ & $\mathrm{X}$ & $\mathrm{X}$ & $\mathrm{X}$ & & & & \\
\hline - $\quad$ Falls with injury & $\mathrm{X}$ & $\mathrm{X}$ & & $\mathrm{X}$ & & & & \\
\hline - $\quad$ Restraint prevalence & & $\mathrm{X}$ & & $\mathrm{X}$ & & & & \\
\hline $\begin{array}{l}\text { - Catheter-associated urinary tract infections for } \\
\text { ICU patients }\end{array}$ & & & & $\mathrm{X}$ & & $\mathrm{X}^{*}$ & $X^{*}$ & \\
\hline $\begin{array}{ll} & \text { Central line catheter-associated blood stream } \\
\text { infection rate for ICU and HRN patients }\end{array}$ & & & & $\mathrm{X}$ & & $\mathrm{X}^{*}$ & $X^{*}$ & $\mathrm{X}^{*}$ \\
\hline - $\quad$ Smoking cessation counseling for AMI & & & & & $\mathrm{X}^{* *}$ & & & \\
\hline - $\quad$ Smoking cessation counseling for HF & & & & & $\mathrm{X}^{* *}$ & & & \\
\hline - Smoking cessation counseling for pneumonia & & & & & $\mathrm{X}^{* *}$ & & & \\
\hline - $\quad$ Skill mix (RN, LVN/LPN, UAP, and contract) & $\mathrm{X}$ & $\mathrm{X}$ & $\mathrm{X}$ & $\mathrm{X}$ & & & & \\
\hline - $\quad$ Nursing care hours per patient day & $\mathrm{X}$ & $\mathrm{X}$ & $\mathrm{X}$ & $\mathrm{X}$ & & & & \\
\hline - $\quad$ Practice environment scale & & $\mathrm{X}$ & $\mathrm{X}$ & $\mathrm{X}$ & & & & \\
\hline - $\quad$ Voluntary turnover & $\mathrm{X}$ & & $\mathrm{X}$ & $\mathrm{X}$ & & & & \\
\hline
\end{tabular}


Note: Blank space indicates not applicable; $(-)=$ no data available; $(*)=$ not verbatim use of endorsed measure; $\left({ }^{*}\right)=$ previously included in TJC Core Measures but discontinued in 2010 (The Joint Commission, 2015c); AHRQ = Agency for Healthcare Research $\&$ Quality; CALNOC $=$ Collaborative Alliance for Nursing Outcomes; CMS = Center for Medicare \& Medicaid Services; HRN = high-risk nursery; ICU = intensive care unit; INQIP = Inpatient Nursing Quality Indicators Project; LVN/LPN = licensed vocational nurse/licensed practical nurse; MilNOD = Military Nursing Outcomes Database; NDNQI = National Database of Nursing Quality Indicators $^{\mathrm{TM}} ; \mathrm{RN}=$ registered nurse $; \mathrm{TJC}=$ The Joint Commission; UAP $=$ unlicensed assistive personnel; UHC $=$ University HealthSystem Consortium; VANOD = Veterans Affairs Nursing Outcomes Database.

a (Brown, Donaldson, Bolton, \& Aydin, 2010)

b (Patrician, Loan, McCarthy, Brosch, \& Davey, 2010)

c (Collins, 2009; Kutney-Lee, Brennan, Meterko, \& Ersek, 2015)

d (Gajewski, Lee, \& Dunton, 2012; Montalvo, 2007)

e (excludes Hospital Outpatient Department measures; TJC, 2015b)

f (TJC, 2015d)

g (Centers for Disease Control and Prevention, 2015; Center for Medicare \& Medicaid Services, 2015b)

h (AHRQ, 2015c, 2015d, 2015e) 


\section{Table 3}

\section{Empirically Demonstrated Relationships Between Estimates of Unfinished Nursing Care and}

\section{Significantly Related Factors}

\begin{tabular}{|c|c|c|}
\hline & Statistic & Source \\
\hline $\begin{array}{l}\text { Nursing Work Environment } \\
\text { Essentials of Magnetism II } \\
\text { Total score } \\
\text { Perceived adequacy of staffing } \\
\text { subscale } \\
\text { Nursing Work Index-Revised } \\
\text { Total score } \\
\text { Nursing resources subscale }\end{array}$ & $\begin{array}{l}r=-0.46 \\
r=-0.46 \text { to }-0.67\end{array}$ & $\begin{array}{l}\text { Schubert et al., } 2007 \text {; } \\
\text { Schubert et al., } 2008\end{array}$ \\
\hline $\begin{array}{l}\text { Patient Outcomes } \\
\text { Patient Satisfaction }\end{array}$ & $O R=0.3$ to 0.6 & $\begin{array}{l}\text { Ausserhofer et al., 2013; } \\
\text { Schubert et al., } 2007\end{array}$ \\
\hline Overall quality of care & $r=-0.37$ to -0.63 & $\begin{array}{l}\text { Ball et al., 2013; Jones, 2014; } \\
\text { Sochalski, } 2004\end{array}$ \\
\hline Medication errors & $O R=2.5$ & $\begin{array}{l}\text { Ausserhofer et al., 2013; Lucero, } \\
\text { Lake, \& Aiken, 2010; Schubert et } \\
\text { al., } 2007\end{array}$ \\
\hline Inpatient mortality & $O R=1.5$ & $\begin{array}{l}\text { Schubert, Clarke, Aiken, \& De } \\
\text { Geest, } 2012\end{array}$ \\
\hline Patient falls & $\begin{array}{l}O R=1.7 \text { to } 2.4 \\
r=0.30\end{array}$ & $\begin{array}{l}\text { Ausserhofer et al., 2013; Kalisch, } \\
\text { Tschannen, \& Lee, 2012; Schubert } \\
\text { et al., 2008; Schubert, Clarke, } \\
\text { Glass, Schaffert-Witvliet, \& De } \\
\text { Geest, } 2009\end{array}$ \\
\hline Pressure ulcers & $O R=1.2$ to 3.4 & $\begin{array}{l}\text { Ausserhofer et al., 2013; Schubert } \\
\text { et al., 2007; Schubert et al., } 2009\end{array}$ \\
\hline Nosocomial infections & $O R=1.3$ to 3.0 & $\begin{array}{l}\text { Ausserhofer et al., 2013; Lucero et } \\
\text { al., 2009; Lucero et al., 2010; } \\
\text { Rochefort \& Clark, 2010; Schubert } \\
\text { et al., } 2009\end{array}$ \\
\hline 30-day readmissions & $O R=1.01$ to 1.12 & $\begin{array}{l}\text { Brooks Carthon, Lasater, Sloane, } \\
\& \text { Kutney-Lee, } 2015\end{array}$ \\
\hline \multicolumn{3}{|l|}{ Nursing Outcomes } \\
\hline $\begin{array}{l}\text { Nurse job satisfaction } \\
\text { Nurse occupational satisfaction } \\
\text { Nurse turnover } \\
\text { Nurse intent to leave }\end{array}$ & $\begin{aligned} r & =0.48 \\
r & =0.6 \\
r & =0.2 \\
r & =0.4\end{aligned}$ & $\begin{array}{l}\text { Jones, } 2014 \\
\text { Kalisch, Tschannen, \& Lee, } 2011 \\
\text { Tschannen, Kalisch, \& Lee, } 2010 \\
\text { Tschannen et al., } 2010\end{array}$ \\
\hline
\end{tabular}

Note. All relationships are significant at $\mathrm{p} \leq 0.05 . r=$ Pearson correlation coefficient; $O R=$ odds ratio. Adapted from "Unfinished Nursing Care, Missed Care, and Implicitly Rationed Care: State 
of the Science Review," by T. L. Jones, P. Hamilton, and N. Murry, 2015, International Journal of Nursing Studies, 52, p. 1132. Used with permission. Copyright 2015 by Elsevier Publishing. 


\section{Figures}

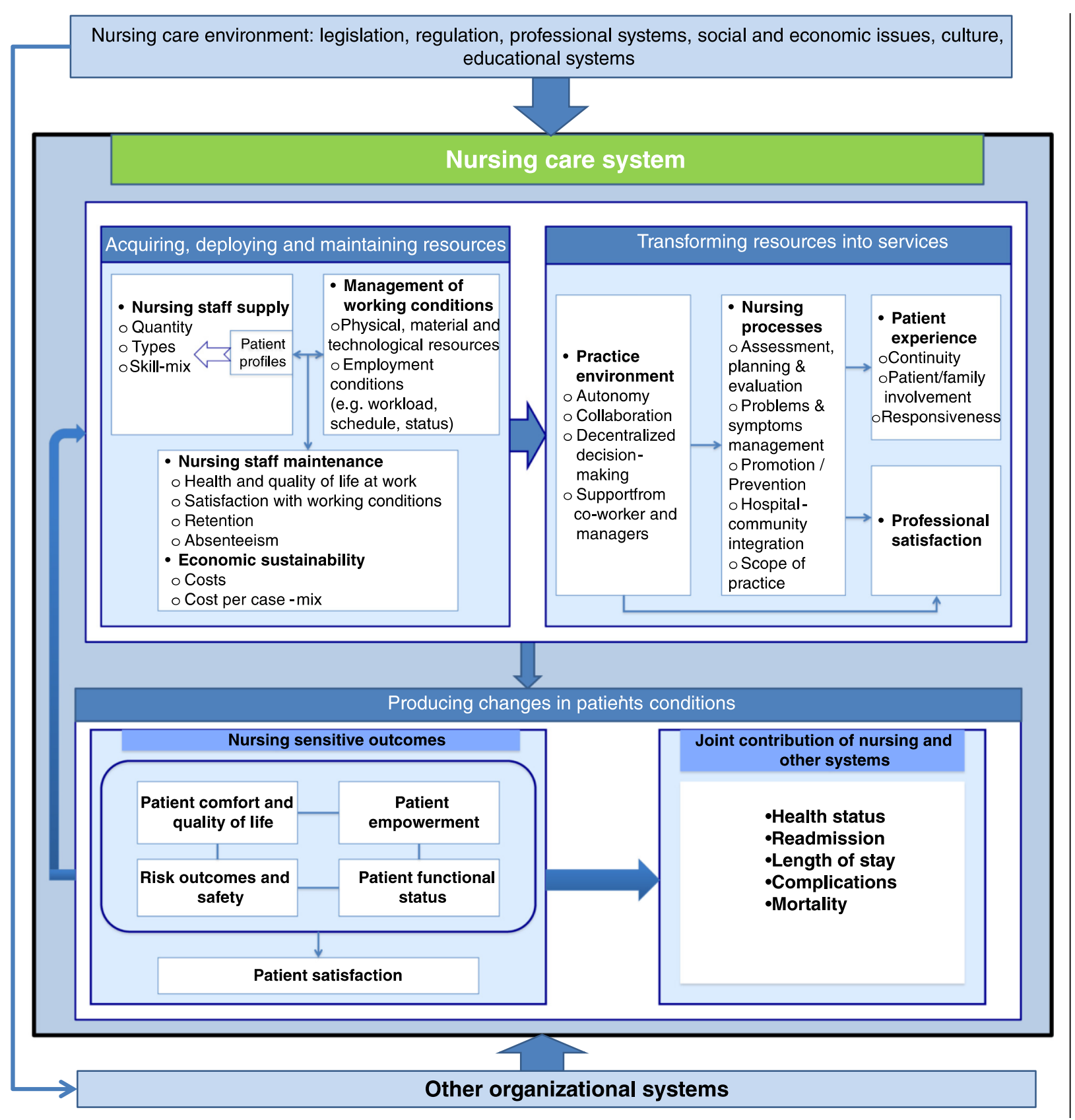

Figure 1. Nursing Care Performance Framework. From "Conceptualizing Performance of

Nursing Care as a Prerequisite for Better Measurement: A Systematic and Interpretive Review,"

by C. A. Dubois, D. D’Amour, M. R. Pomey, F. Girard, and I. Brault, 2013, BMC Nursing, 12, p. 
17. Copyright 2013 by BioMed Central, Ltd. Used with permission of BioMed Central, Ltd., in accordance with the terms of the Creative Commons Attribution License. 